\section{Evaluating Dose-response of Cataract Induction in Radiotherapy of Head and Neck Cancers Patients}

\author{
Arefpour A. M. ${ }^{1 \oplus}$, Bahrami M. ${ }^{2}$, Haghparast A. ${ }^{*}{ }^{\oplus}$, Khosh- \\ gard K. ${ }^{3}$, Aryaei Tabar H. ${ }^{4}$, Farshchian N. ${ }^{5}$
}

\begin{abstract}
Background: Head and neck cancers are currently the most common types of cancers. 3D-conformal radiation therapy is the most common dose delivery technique for head and neck cancers. Eye Lens is a radio sensitive structure and cataract formation as a visual disorder associated with exposure to ionizing radiation which is documented.
\end{abstract}

Objective: Determining the radiation dose to eye lens during head and neck radiography and estimating the probability of cataract induction are essential.

Material and Methods: This experimental study was performed on 14 patients with head and neck cancers through experimental study analysis. The maximum opacity of the eyes lens were measured by pentacam ${ }^{\mathrm{TM}}$ before radiation therapy. CT data of patients were transmitted to Isogray treatment planning Software, and dose calculations for each patient was performed. At the end of radiation treatment, 3 and 6 months after radiotherapy, the eye lens opacity of the patients was assessed.

Results: Overall, 28 lenses were studied. Statistical one sample K- $\mathrm{S}$ test proved normality of obtained data. Using repeated measures test, the relation before and 3 months after radiotherapy, as well as the relationship before and 6 months after radiotherapy proved a significant relationship.

Conclusion: The opacity caused by radiation in eyes is a non-statistical and linear-quadratic response curve with no threshold. This opacity can also appear within 3 months after completion of radiation therapy.

Citation: Arefpour AM, Bahrami M, Haghparast A, Khoshgard K, Aryaei Tabar H, Farshchian N. Evaluating Dose-response of Cataract Induction in Radiotherapy of Head and Neck Cancers Patients. J Biomed Phys Eng. 2021;11(1):9-16. doi: 10.31661/jbpe.v0i0.834.

\section{Keywords}

Head and Neck Cancers; Radiotherapy; Cataract; Eye Lens Absorbed Dose; Radiation Dosage

\section{Introduction}

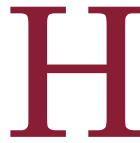
ead and neck cancers (HNCs) are the most dangerous types of cancers. Because of proximity of tumor site to the neck lymph nodes, development of cancer to other parts of body is at a high risk, and so, they are much better to be treated quickly. HNC is a general term which involves malignant tumors of breathing and superior gastrointestinal regions including the oral cavity, nasopharynx, oropharynx, hypopharynx, Larynx and salivary glands [1]. It is estimated that 644 thousand new cases of HNCs are reported annually worldwide among which two-thirds of cases occur in developing countries. The population
${ }^{1} \mathrm{MD}$, Department of

Radiation Oncology,

Faculty of Medicine, Iran

University of Medical Sci-

ences, Tehran, Iran

${ }^{2} \mathrm{MSc}$, Department of

Medical Physics, Faculty

of Medicine, Kerman-

shah University of Medi-

cal Sciences, Kerman-

shah, Iran

${ }^{3} \mathrm{PhD}$, Department of

Medical Physics, Faculty

of Medicine, Kerman-

shah University of Medi-

cal Sciences, Kerman-

shah, Iran

${ }^{4} \mathrm{MD}$, Departments of

Ophthalmology, Faculty

of Medicine, Kerman-

shah University of Medi-

cal Sciences, Kerman-

shah, Iran

${ }^{5} \mathrm{MD}$, Department of

Radiation Oncology,

Faculty of Medicine,

Kermanshah University

of Medical Sciences,

Kermanshah, Iran

*Corresponding author:

A. Haghparast

Department of Medi-

cal Physics, Faculty of

Medicine, Kermanshah

University of Medical

Sciences, Kermanshah, Iran

E-mail: abbas.haghparast@gmail.com

Received: 10 September 2017 Accepted: 16 November 2017 
at risk of these types of cancers are people with long-term history of smoking and drinking. However, the statistical rate, age and gender of patients in several studies in recent decades have been changing. Such as the fact that this type of cancer is more common in men, but its incidence in women has increased [2]. Radiation therapy by high energy X-rays or other ionizing particles for the destruction of cancer cells are used. Radiation therapy is usually given a diet containing a certain number of doses of radiation during certain meetings and certain time. Radiation therapy is mainly used for HNC treatment, especially after surgery or for the cases in which tomural cells cannot be removed by surgery [3]. Eye lens is a radio sensitive structure, and cataracts as a side effect associated with exposure to ionizing radiation has been documented [4]. Cataracts also is the most common cause of blindness worldwide [5]. The major risk factors for developing cataracts include: congenital cataracts due to age, diabetes, corticosteroids use, nicotine and alcohol usage, exposure to non-ionizing radiation and ionizing radiation $[6,7]$. Based on clinical appearance, cataracts can be defined as three main types: central cataracts (opacities are mainly located at the center of lens), cortical cataracts (opacities are mainly peripheral and central parts gradually drawn), and subcapsular cataract (which forms in the back of lens) [7, 8]. Cataract is caused by radiation because of irradiation to germinative area. When dividing cells of this (germinative) are damaged due to radiation effects, abnormal lens fibers are not removed and disposed, therefore, cataract formation will begin. The incubation period and the severity of radiation-induced cataracts depend on radiation dose, dose rate and fractionation. It has been reported that the incubation period for the development of radiation-induced cataracts is inversely related to the dose of radiation [9].

The tolerance dose of 2 Gy at chronic and 4 Gy at acute exposures for radiation-induced cataract had been reported by International Committee of Radiobiological Protection (ICRP) publication No.103 in 2007 [10, 11]. In 2006 Nakashima et al., analyzed this threshold dose for cataracts in the atomic-bomb survivors; the number of 873 persons aged less than 13 years were considered, and examinations were performed at the age of 55. In this study, a threshold equivalent dose of $0.6 \mathrm{~Sv}$ was reported [12]. In 2011, ICRP at its publication No.118, reported the lowest threshold dose of 0.5 Gy for the lens of the eyes to create the opacity [13].

The aim of this study was determining the dose-response curve of radiation induced cataracts during a 6 months the follow-up in patients with head and neck cancers.

\section{Material and Methods}

In this experimental study, 14 patients with head and neck cancers were considered. Inclusion criteria consisted of a primary malignancy in head and neck region needing to receive radiation therapy as primary or complementary treatment. All patients were enrolled with personal satisfaction.

Both eyes of the patients were examined using Pentacam (Oculus-Germany) to measure the maximum opacity of the lens of the eye at a point; (measuring the average opacity caused by radiation, over a period of more than 6 months after completion of radiation therapy can be significant, so the maximum opacity in the lens of the eye was measured at one point). CT-scan (Toshiba, Japan) for all patients was done before treatment planning with $120 \mathrm{KVp}, 200 \mathrm{~mA}$ and 4- mm slice thickness. Patients were immobilized with thermoplastic masks during imaging. CT data of each patient was transferred to treatment planning software (Isogray, DosiSoft, France), and treatment planning in head and neck region was performed on tumor volume. The eye lenses were identified and planned as healthy organs at risk. Radiation therapy was done as three dimensional conformal radiation therapy 
(3D-CRT) method, and irradiations to tumor site were done by technique using a linear accelerator (ELEKTA, England).

\section{Results}

In this study, 14 patients with mean age of $55.64 \pm 11$ years (range; $39-72$ years) were studied. Of the patients, 6 patients $(42.86 \%)$ parotid cancer, 5 patients $(35.7 \%)$ Laryngeal cancer and 3 patients $(21.43 \%)$ had been suffering from a brain tumor. Also, 5 patients (35.7\%) had smoking habit, and 10 patients $(71.43 \%)$ had concurrent chemotherapy. All patients had no history of any previous eye surgery or diabetes (Table 1).

The data of prescribed dose and dose received by eyes lenses are tabulated in Table 2 . The absorbed dose of left and right eye lenses were in the range of 1-2000 cGy and 1-2293 cGy, respectively.

The maximum opacity of the eye lenses of the patients before, after 3 months and 6 months after radiotherapy are listed in Table 3. Since left and right eye lenses are physiologically independent and opacity in one eye will have no effect on the other eye, left and right eye lenses (28 ones) were considered separately. The average \pm standard deviation of maximum opacity induced in the lenses of the eyes before, 3 months after radiotherapy and 6 months after radiotherapy are shown in Table 4. One sample K-S test showed the distribution of the obtained data was normal. In addition, the repeated measures test used to check the significant relationship before and after radiation therapy measurements. The uniformity of covariance was tested with Mauchly test (SPSS, V. 20); the significance level of the test was obtained less than $0.05(\mathrm{p}=0)$. PValue is offered in Sphericity rows-Sphericity Assumed $(p=0)$, Greenhouse-Geisser $(p=0)$, Huynh-Feldt $(p=0)$ and lower-bound $(p=0)$ the analysis of variance was less than 0.05 . Statistical analysis of repeated measurements demonstrated a statistically and clinically significant relationship between the opacity before and 3 months after radiation therapy $(p=0)$, as well as before and 6 months after radiation therapy $(p=0)$. Then, Curve fitting for the series of maximum opacity as the measured data

Table 1: Demographic information of the patients.

\begin{tabular}{cccccccc}
$\begin{array}{c}\text { Patient's } \\
\text { code }\end{array}$ & Sex & $\begin{array}{c}\text { Age } \\
\text { (years) }\end{array}$ & $\begin{array}{c}\text { Duration of smoking } \\
\text { (years) }\end{array}$ & $\begin{array}{c}\text { Tumor } \\
\text { Bed }\end{array}$ & Chemotherapy & $\begin{array}{c}\text { History of } \\
\text { eye Surgery }\end{array}$ & Diabetic \\
\hline 1 & M & 39 & 20 & parotid & Yes & No & No \\
\hline 2 & F & 40 & 0 & parotid & Yes & No & No \\
\hline 3 & F & 63 & 0 & parotid & No & No & No \\
\hline 4 & M & 72 & 0 & Laryngeal & Yes & No & No \\
\hline 5 & M & 50 & 20 & Laryngeal & Yes & No & No \\
\hline 6 & M & 65 & 50 & Laryngeal & No & No & No \\
\hline 7 & M & 44 & 22 & Laryngeal & Yes & No & No \\
\hline 8 & M & 63 & 0 & brain & No & No & No \\
\hline 9 & M & 69 & 0 & Laryngeal & Yes & No & No \\
\hline 10 & M & 51 & 0 & brain & Yes & No & No \\
\hline 11 & F & 58 & 0 & parotid & No & No & No \\
\hline 12 & M & 60 & 40 & parotid & Yes & No & No \\
\hline 13 & M & 42 & 0 & brain & Yes & No & No \\
\hline 14 & F & 61 & 0 & parotid & Yes & No & No
\end{tabular}


Table 2: Dosimetric data of the patients.

\begin{tabular}{cccccc}
$\begin{array}{c}\text { Patient } \\
\text { code }\end{array}$ & $\begin{array}{c}\text { Energy } \\
\text { (MV) }\end{array}$ & $\begin{array}{c}\text { Prescribed dose } \\
\text { (cGy) }\end{array}$ & $\begin{array}{c}\text { Number of } \\
\text { fractions }\end{array}$ & $\begin{array}{c}\text { Left eye lens } \\
\text { dose (cGy) }\end{array}$ & $\begin{array}{c}\text { Right eye lens } \\
\text { dose (cGy) }\end{array}$ \\
\hline 1 & 6 & 4600 & 23 & 102 & 102 \\
\hline 2 & 6 & 6600 & 33 & 1042 & 1787 \\
\hline 3 & 6 & 2000 & 22 & 133 & 90 \\
\hline 4 & 6 & 7000 & 35 & 70 & 60 \\
\hline 5 & 6 & 4600 & 23 & 1 & 1 \\
\hline 6 & 6 & 7000 & 35 & 120 & 51 \\
\hline 7 & 6 & 4600 & 23 & 48 & 227 \\
\hline 8 & 6 & 4600 & 23 & 228 & 57 \\
\hline 9 & 6 & 4600 & 23 & 54 & 2293 \\
\hline 10 & 6 & 5000 & 25 & 2000 & 368.1 \\
\hline 11 & 6 & 4000 & 21 & 330.6 & 1600 \\
\hline 12 & 6 & 4600 & 23 & 700 & 1260 \\
\hline 13 & 6 & 5400 & 30 & 1500 & 600
\end{tabular}

Table 3: Maximum opacity of the eyes lens of the patients before, 3 months and 6 months after radiation therapy $(\mathrm{RT})$.

Max opacity before radia- Max opacity at 3 months after tion therapy (RT) (\%)

\begin{tabular}{ccccccc} 
& \multicolumn{2}{c}{ tion therapy $\mathbf{( R T )}(\mathbf{\%})$} & \multicolumn{2}{c}{ radiation therapy $\mathbf{( R T )}(\mathbf{\%})$} & \multicolumn{2}{c}{ months after RT (\%) } \\
\hline Patient No. & Left lens & Right lens & Left lens & Right lens & Left lens & Right lens \\
\hline 1 & 58 & 65.1 & 59.1 & 67.1 & 59.6 & 67.9 \\
\hline 2 & 33.3 & 52.9 & 39.2 & 65.2 & 41.8 & 68.1 \\
\hline 3 & 12.9 & 22 & 13.7 & 22.7 & 14.9 & 24.9 \\
\hline 4 & 51 & 61.2 & 52.6 & 63 & 53.9 & 63.6 \\
\hline 5 & 25.5 & 29 & 27 & 30.2 & 28.7 & 30.8 \\
\hline 6 & 52.2 & 47.5 & 53.6 & 48.6 & 54.9 & 49 \\
\hline 7 & 77.6 & 78 & 78.5 & 79.2 & 79.2 & 79.6 \\
\hline 8 & 54.5 & 52.2 & 55.8 & 53.3 & 57.3 & 54.1 \\
\hline 9 & 38.4 & 34.9 & 39.9 & 35.9 & 40.5 & 36.2 \\
\hline 10 & 34.5 & 38.8 & 45.7 & 51.9 & 50.3 & 55.3 \\
\hline 11 & 38 & 30.6 & 38.4 & 32.3 & 39.2 & 32.8 \\
\hline 12 & 30.2 & 34.5 & 32.7 & 46.8 & 34.8 & 49.7 \\
\hline 13 & 27.8 & 36.1 & 33.3 & 42.2 & 35.7 & 44.8 \\
\hline 14 & 27.5 & 28.6 & 28.9 & 30.8 & 30.4 & 31.8
\end{tabular}


Table 4: Mean and standard deviation of opacity at a point of the lenses.

Mean \pm SD

Before radiation therapy $41.89 \pm 16.3$ 3 months after radiation therapy $45.27 \pm 16.35$ $46.78 \pm 16.24$

points were done and then shown in Figures 1, 2, 3 and Table 4.

Equations 1 and 2, respectively correspond to Figures 2 and 3 were determined using MATLAB software (version 2016) in which $\mathrm{x}=$ Eye lens dose $(\mathrm{Gy}), \mathrm{Y}=$ maximum opacity $(\%)$.

$$
\begin{aligned}
& Y=0.131 X^{1.475}+1.23 \\
& Y=0.2066 X^{1.397}+1.862
\end{aligned}
$$

\section{Discussion}

Radiation dosimetry in radiation therapy (RT) has a great importance; successful RT requires precise radiation dose delivery to can-

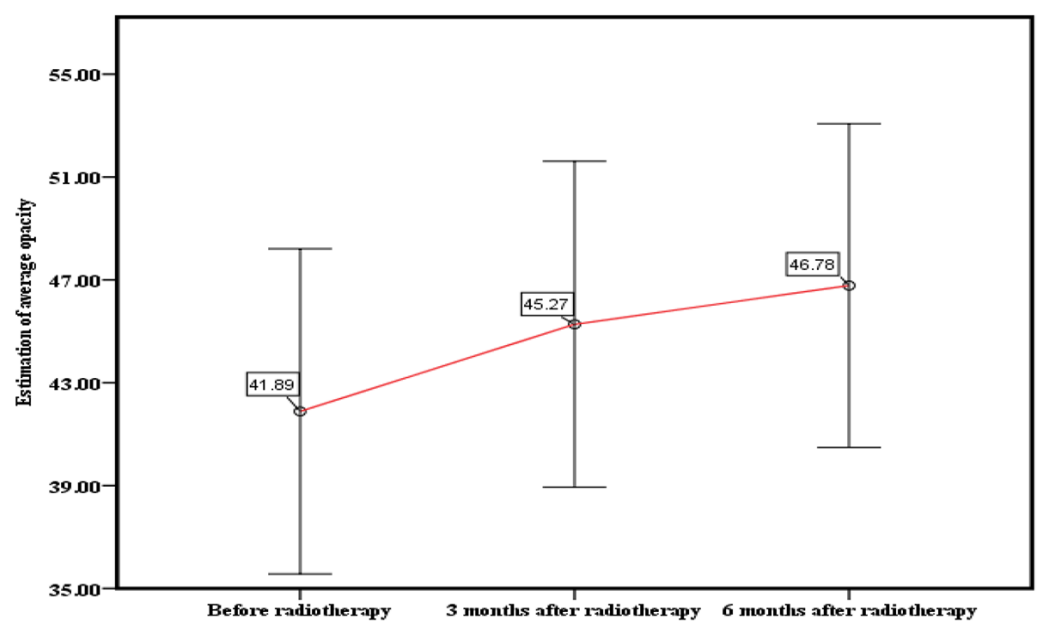

Figure 1: Changes in average opacity of the patients' eye lens from before radiation therapy to 6 months after radiation therapy

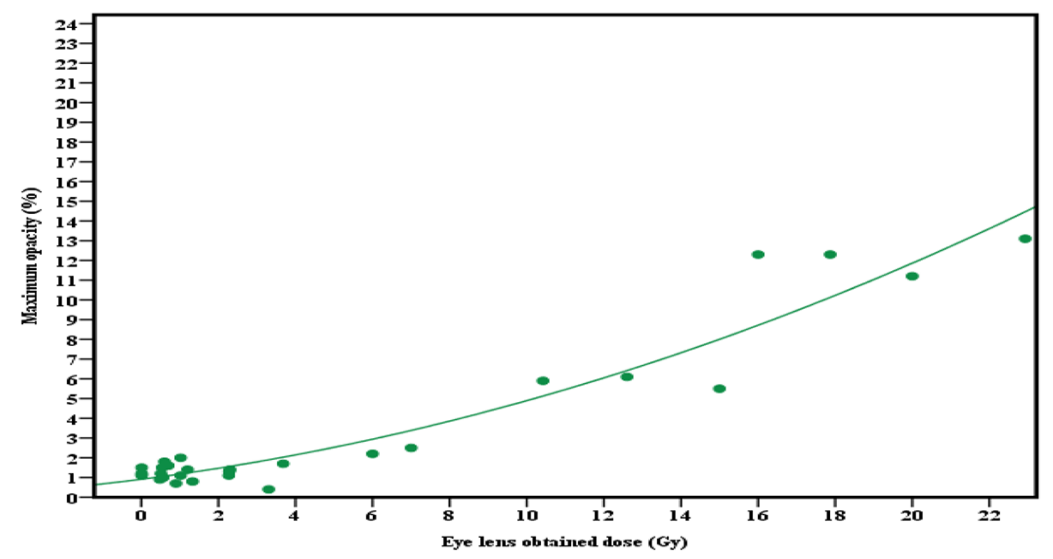

Figure 2: Maximum opacity of the eye lens in 3 months after radiation therapy. 


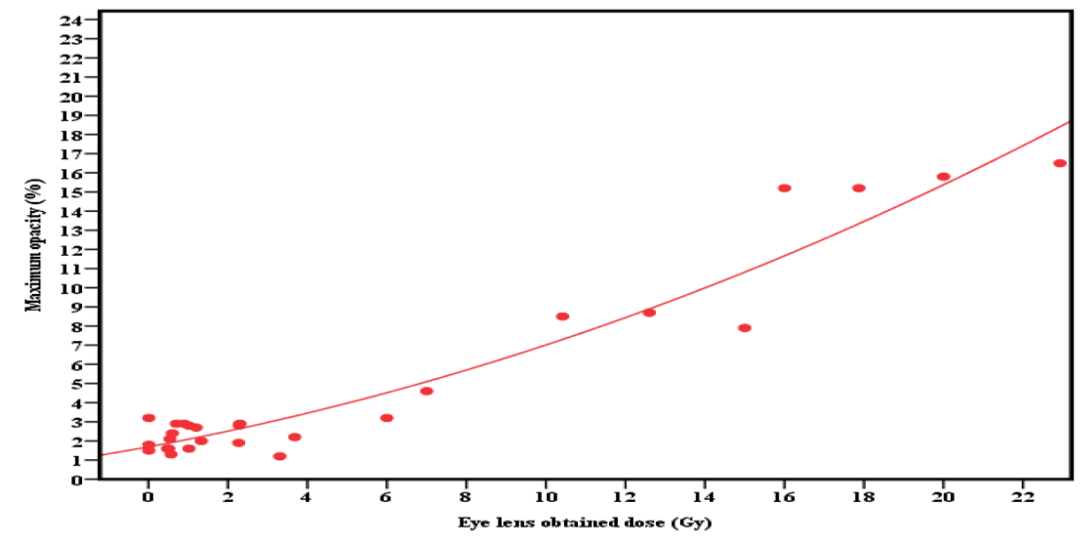

Figure 3: Maximum opacity of the eye lens in 6 months after radiation therapy

cer tissue volume, so the lowest dose received by surrounding healthy tissue. As a general rule, one must try healthy tissues to get minimal dose while the lethal and uniform radiation doses are delivered to tomural tissue.

Over the years, radiologists have known the lens might be damaged by radiation. Study of patients treated with $\mathrm{X}$ - and gamma rays showed the formation of cataract caused by radiation exposure in human. Cataract caused by radiation in most cases is naturally different from the lesions caused by natural factors or other complex types of cataract.

Most cases were subcapsular and central cataracts. However, other studies have shown the opacity caused by radiation ordinarily including: subcapsular, cortical and central cataracts. Richard et al., [14] investigated the cataract caused by microwave radiation, ionizing radiation and concluded that cataract induced by ionizing radiation (e.g., X- and gamma rays) are often in the form of a cataract subcapsular. In 1999, Hall et al., [15] investigated the correlation between dose and induction of cataract lens in children less than 18 months with skin hemangioma treated with ionizing radiation. A number of 484 patients exposed to radiation (with mean dose of lenses of 0.4 Gy and rage of 0 to 8.4 Gy) were considered, and inductions of lens opacity were studied all at the age of 36-45 years for all patients. As a result, 357 of patients were affected by subcapsular and cortical cataract [15]. Minamoto et al., [16] studied the cataract in atomic bomb survivors ( 873 people) who were exposed to ionizing radiation in their ages of under 13 years (with estimation doses of $2 \mathrm{~Gy}$ to eye lens) and the opacity of the eye lens investigated at age 55; they reported that most of the people had cortical, subcapsular and central. In 2006, Nakashima et al., [12] re-analyzed cataract threshold dose in atomic bomb survivors. The number of 873 persons aged less than 13 years were considered, and examinations were conducted at age 55. Subcapsular and cortical cataracts were common types.

There is different latent period for the induction of cataract from 6 months to more than 50 years in literature. It has been reported that cataract latent period becomes shorter with increasing dose. According to our results, the opacity can occur within 3 months after the completion of radiation therapy. The results of several studies suggest that a radiation-induced cataract is a definite late effect [9].

Based on this study, dose- response of the curve for radiation-induced cataracts is a upward concave liner-quadratic curve with any threshold dose. Wilde et al., [17] studied the cataract formation in adults whose eye lenses were irradiated with radium-226. Many years in their study, 20 children (age 2-13 months) 
Cataract Induction in Radiotherapy

with hemangioma of the eyelid and surrounding tissue irradiated with gamma rays of radium-226 sources were examined at the age of 31 to 46 years by Slit-lamp. In their study, the eye lens with an average dose of 1-8 Gy suffered from cataract, and the minimum dose to cause turbidity was obtained as $0.1 \mathrm{~Gy}$ [17]. In a clinical study of cataract caused by acute exposure, radiation dose for induction of opacity in eye lenses was obtained as 1.3 Gy [18]. Dig et al., [19] have reported the observed dose of 4-15 Gy for cataract formation in patients who received whole body radiation. ICRP No. 60 in 1990 and 103 in 2007, published tolerance dose of 2 Gy in chronic exposure and 4 Gy in acute radiation for cataract formation $[11,10]$. In another study, absorbed doses of 3 Gy with threshold dose of about 0.8 Gy have been reported for atomic bomb survivors two years after exposure to ionizing radiation [20]. The International Committee of Radiobiological Protection at No. 118 (2011) has reported the lowest dose of about 0.5 Gy as a threshold dose for inducing cataract in lens [10]. Based on the review conducted in 2009 by Ainsbury et al., [21] it has been reported that the threshold dose has a decreasing trend, and cataract is a definite effect which can be more accurately definable by a linear model without threshold. In another study, the prevalence of cataract 12 to14 years after exposure among Chernobyl workers has been studied; and as a result, a liner-quadratic curve with upward concavity was proposed for radiation-induced cataract [22]. It is recommended that all patients with head and neck cancers, even when the eyes are located outside the radiation field, should be protected using eye shields.

\section{Conclusion}

The opacity can appear within 3 months after radiation therapy of head and neck cancers. Radiation-induced cataract is a definite effect, its dose-response curve is liner-quadratic with no threshold dose. Radiation-induced cataracts ordinarily include subcapsule, cortical and central.

\section{Acknowledgment}

Authors gratefully acknowledge the Research Council of Kermanshah University of Medical Sciences for the financial support. This work (Grant Number: 93503) was performed in the partial fulfillment of the requirements for the degree of Master of Science by Mohammad Bahrami, in the Faculty of Medicine, Kermanshah University of Medical Sciences, Kermanshah, Iran.

\section{Conflict of Interest}

None

\section{References}

1. Dobrossy L. Epidemiology of head and neck cancer: magnitude of the problem. Cancer Metastasis Rev. 2005;24:9-17. doi: 10.1007/s10555-0055044-4. PubMed PMID: 15785869.

2. Chidzonga MM, Mahomva L. Squamous cell carcinoma of the oral cavity, maxillary antrum and lip in a Zimbabwean population: a descriptive epidemiological study. Oral Oncol. 2006;42:184-9. doi: 10.1016/j.oraloncology.2005.07.011. PubMed PMID: 16256417.

3. Jacob S, Michel M, Brezin A, Laurier D, Bernier $M$. Ionizing radiation as a risk factor for cataract: what about low-dose effects. J Clin Exp Ophthalmol S. 2012;1.

4. Otake M, Schull WJ. A review of forty-five years study of Hiroshima and Nagasaki atomic bomb survivors. Radiation cataract. J Radiat Res. 1991;32 Suppl:283-93. PubMed PMID: 1762117.

5. Roodhooft JM. Leading causes of blindness worldwide. Bull Soc Belge Ophtalmol. 2002:1925. PubMed PMID: 12058483.

6. Abraham AG, Condon NG, West Gower E. The new epidemiology of cataract. Ophthalmol Clin North Am. 2006;19:415-25. doi: 10.1016/j. ohc.2006.07.008. PubMed PMID: 17067897.

7. Asbell PA, Dualan I, Mindel J, Brocks D, Ahmad M, Epstein S. Age-related cataract. Lancet. 2005;365:599-609. doi: 10.1016/S01406736(05)17911-2. PubMed PMID: 15708105.

8. Graw J. The genetic and molecular basis of congenital eye defects. Nat Rev Genet. 2003;4:876-88. doi: 10.1038/nrg1202. PubMed PMID: 14634635.

9. Merriam GR, Worgul BV. Experimental radiation 
cataract--its clinical relevance. Bull N Y Acad Med. 1983;59:372-92. PubMed PMID: 6575847. PubMed PMCID: PMC1911644.

10. ICRP. 1990 Recommendations of the International Commission on Radiological Protection. ICRP; Amsterdam: Elsevier; 1991.

11. ICRP. The 2007 Recommendations of the International Commission on Radiological Protection. Ann ICRP. 2007;37:1-332. doi: 10.1016/j. icrp.2007.10.003. PubMed PMID: 18082557.

12. Nakashima E, Neriishi K, Minamoto A. A reanalysis of atomic-bomb cataract data, 2000-2002: a threshold analysis. Health Phys. 2006;90:154-60. PubMed PMID: 16404173.

13. Thorne MC. Regulating exposure of the lens of the eye to ionising radiations. $J$ Radiol Prot. 2012;32:147-54. doi: 10.1088/09524746/32/2/147. PubMed PMID: 22555212.

14. Lipman RM, Tripathi BJ, Tripathi RC. Cataracts induced by microwave and ionizing radiation. Surv Ophthalmol. 1988;33:200-10. PubMed PMID: 3068822.

15. Hall P, Granath F, Lundell M, Olsson K, Holm LE. Lenticular opacities in individuals exposed to ionizing radiation in infancy. Radiat Res. 1999:152:190-5.

16. Minamoto A, Taniguchi H, Yoshitani N, Mukai $\mathrm{S}$, Yokoyama $\mathrm{T}$, et al. Cataract in atomic bomb survivors. Int J Radiat Biol. 2004;80:339-45. doi: $10.1080 / 09553000410001680332$.
17. Wilde G, Sjostrand J. A clinical study of radiation cataract formation in adult life following gamma irradiation of the lens in early childhood. Br J Ophthalmol. 1997;81:261-6. PubMed PMID: 9215051. PubMed PMCID: PMC1722161.

18. Merriam Jr GR, Focht EF. A clinical study of radiation cataracts and the relationship to dose. $\mathrm{Am} \mathrm{J}$ Roentgenol Radium Ther Nucl Med. 1957;77:75985. PubMed PMID: 13411351.

19. Deeg HJ, Flournoy N, Sullivan KM, Sheehan K, Buckner CD, Sanders JE, et al. Cataracts after total body irradiation and marrow transplantation: a sparing effect of dose fractionation. Int $J$ Radiat Oncol Biol Phys. 1984;10:957-64. PubMed PMID: 6378850.

20. Neriishi K, Nakashima E, Minamoto A, Fujiwara S, Akahoshi M, Mishima HK, et al. Postoperative cataract cases among atomic bomb survivors: radiation dose response and threshold. Radiat Res. 2007;168:404-8. doi: 10.1667/RR0928.1. PubMed PMID: 17903036.

21. Ainsbury E, Bouffler S, Dörr W, Graw J, Muirhead C, Edwards A, et al. Radiation cataractogenesis: a review of recent studies. Radiat Res. 2009;172:19.

22. Worgul BV, Kundiyev YI, Sergiyenko NM, Chumak VV, Vitte PM, Medvedovsky C, et al. Cataracts among Chernobyl clean-up workers: implications regarding permissible eye exposures. Radiat Res. 2007;167:233-43. PubMed PMID: 17390731. 